\title{
Structural Performance of Limestone as An Aggregate for Lightweight Concrete
}

\author{
R. O. Onchiri \\ Department of Building and Civil Engineering, \\ Technical University of Mombasa \\ P.O.Box 90420-80100
}

\begin{abstract}
Concrete is composed essentially of cement, aggregates and water. In some cases an admixture is added, generally for the purpose of entraining air, but occasionally for special reasons such as modifying setting time or reducing water content. Lightweight aggregates are available and in use in other parts of the world in the construction industry. These are either processed in a rotary kiln / Sintering grate or natural materials such as pumice and scoria. The study indicates that considerable knowledge has been accumulated on industrial processed lightweight aggregates for use in concrete, but more study needs to be done to determine the effects of other locally available and natural lightweight aggregates like crushed limestone on physical and mechanical properties of concrete. This was done by partial replacement of the granitic aggregates with crushed Limestone as coarse aggregates. The replacement proportions were varied from $0 \%, 25 \%, 50 \%, 75 \%$, and $100 \%$ by weight of natural aggregates. Tests results of this work are of importance in assessing the mechanical properties determined through tensile splitting tests, flexural tests and compressive tests at 3, 7, 14 and 28 days. Crushed limestone (Coral stone) and sand locally available in Mombasa and in specific river sand from Malindi, Limestone Aggregates from Coast Calcium Ltd in Kwale and the Natural Coarse aggregates from Kokotoni where used in this research. This may lead to better and more economical Light weight aggregate for manufacture of masonry units and concrete.
\end{abstract}

Keywords: Limestone, concrete, aggregates, replacement, lightweight, mechanical strength

\section{INTRODUCTION}

Limestone is an organic sedimentary rock composed largely of the minerals calcite and aragonite, which are different crystal forms of calcium carbonate $(\mathrm{CaCO} 3)$. Most limestone is composed of skeletal fragments of marine organisms such as coral, forams and molluscs. Limestone makes up about $10 \%$ of the total volume of all sedimentary rocks. The solubility of limestone in water and weak acid solutions leads to Karst landscapes, in which water erodes the limestone over thousands to millions of years. Most cave systems are through limestone bedrock. Limestone could be the one rock that is used in more ways than any other. Most limestone is made into dressed limestone blocks and used as a construction material. It is used as a road base, railroad ballast and as an aggregate in concrete production. It is used as white pigment or filler in products such as toothpaste or paints, and as a chemical feedstock for the production of lime and cements. Research has been carried out on partial replacement of limestone and silica powder as a substitution of cement in lightweight aggregate concrete Seyed A.Z et al, (2017)
In concrete construction, lightweight concrete is important and solves the concrete self-weight and durability problems in the building industry. The compressive strength, water absorption and workability are significant for the lightweight aggregate concrete. The secret to high quality lightweight structural concrete lies in the aggregate used to produce the mix. The benefit of LWAC as structural material was recognized as far back as Roman days. LWAC has been made from natural vesicular aggregate such as pumice and scoria for over 2000 years. Three of the most notable structures built during the Roman Empire include the Port of Cosa, the Pantheon Dome and the Coliseum. All stand today as testament to the durability of this material, and the Pantheon in particular continues to be used to the present day for the purpose for which it was designed. Minimizing maintenance costs and achieving a long secure life is one of the most important precepts of enhancing sustainability and the Pantheon is an amazing example of this.

Lightweight aggregate concrete is usually defined as a concrete having an air-dry density of below $1850 \mathrm{~kg} / \mathrm{m} 3$ as opposed to a normal concrete having a density of about 2300 $\mathrm{kg} / \mathrm{m} 3$ but a finite limit is undesirable. (Fahrizal Zulkarnain, ICBEDC. 2008)The lightweight concrete has its obvious advantages of high strength/weight ratio, good tensile strength, low coefficient of thermal expansion, and superior heat and sound insulation characteristic due to air voids in lightweight aggregates (Mouli,et al., 2008). LWAC offers design flexibility and substantial cost savings by providing; less dead load, improved seismic structural response, longer spans, and extents.

The reduction in dead weight of a construction results to a decrease in cross-section of structural members and the amount steel reinforcement (Hossain, 2006). Lightweight concrete can either be lightweight aggregate concrete, foamed concrete or autoclaved aerated concrete (AAC). Such lightweight concrete blocks are often used in house construction. Lightweight aggregate concrete can be produced using a variety of lightweight aggregates.

The required properties of the lightweight concrete will have a bearing on the best type of lightweight aggregate to use. If little structural strength is requirement, but high thermal insulation properties, are needed then a light, weak aggregate can be used. This will result in relatively low strength concrete. Lightweight aggregate concrete can, however, be used for structural applications, with strengths equivalent to normal weight concrete. Effect of silica fume on the properties of cement, mortar and concrete is well known, and reported by several authors (Hamid Shahrabadi et al, 2017) 


\section{METHODS AND MATERIALS}

\section{Cement}

Grade CEM I 32.5 N Cement conforming to KS EAS: 18-1: 2001 was used in this study

\section{Fine Aggregates}

These are fractions within the range of 150 micron to $4.75 \mathrm{~mm}$. Fine aggregate used was Malindi sand locally available from local sand suppliers in Mombasa. The aggregates were washed and screened to remove deleterious materials and over size particles. All fine aggregate were cleaned and within requirements of the Kenya standards for natural aggregates for use in concrete (KS 95: 2003).

\section{Course Aggregates}

The coarse aggregates particle size was maintained within the range of $10 \mathrm{~mm}$ to $20 \mathrm{~mm}$ (Mixed aggregates). The natural coarse aggregates (NCA) from Kokotoni, conforming to KS 95: 2003 was used. Coarse Limestone aggregates as LWA used was from Coast Calcium Ltd which is a coast line limestone /coral thus formation by sediments from Dead Sea creatures. The limestone was graded to same size of $10 \mathrm{~mm}$ to 20mm conforming to KS 95: 2003.The flakiness index for the crushed limestone was maintained within the requirements of the Kenya standard for natural aggregates for use in concrete, KS95: 2003.

Due to its porous nature the coral / limestone coarse aggregate were pre-saturated roughly for a period of two hours to control absorption of the water in the concrete mix. To control slump, the limestone aggregates were pre-wetted before being used in the various mixes. This absorbed water is not part of the mix water in the lightweight mix, and it does not directly affect slump, water-cement ratio, or quality of the paste

\section{METHODS}

\section{Sieve Analysis}

This involved dividing the aggregate samples into fractions, each consisting of particles of the same size. In other words this is the gradation tests; the results of sieve analysis are given in terms of $\%$ of the total aggregate passing through each of the sieve size.

Samples were air dried before weighing and sieved by drying to a temperature of $105-110^{\circ} \mathrm{C}$, and the dried sample weighed. The weighed sample was then placed on the sieve and sieved successively on the appropriate sieves starting with the largest.

\section{Specific Gravity}

The sample was washed with clean water to remove the dust and fine particles on the surface of the grain and soaked in water at $25^{\circ} \mathrm{C}$ for 24 hours. The specimen was removed from water, shaken off, and rolled in large absorbent cloth until all the visible films of water is removed.

Each sample was weighed to the nearest $0.5 \mathrm{~g}$ and the weight recorded, as (Ws). Then putted into a wire basket, immersed in water at room temperature, and tapped to remove entrapped air on the surface and between the grains. The immersed aggregates were weight to obtain $\left(\mathrm{W}_{\mathrm{w}}\right)$ and dried in an oven to constant weight at the temperature of $105^{\circ} \mathrm{C}$ and then cool at room temperature and then weigh to the nearest $0.5 \mathrm{~g}$.

\section{Concrete Mix}

Concrete for this research was prepared of the mix proportion 1:2:4 (Cement: fine aggregates: coarse aggregates) by Weight/Volume. For this project, a class $20 \mathrm{mix}$ proportion was adopted which is the cast mix for slabs in the conventional concrete mix. Tests results of this work are of importance in assessing the mechanical properties determined through vane shear tests, flexural tests, and compression strength tests at $3,7,14$ and 28 days.

\section{Workability}

The workability of fresh concrete mixture was determined through slump test in accordance to the Kenya standard methods of testing concrete KS 595 Part 2: 1986.

\section{Tensile strength}

Splitting test was done in accordance to KS 595-4: 1986. Cylindrical moulds of $100 \mathrm{~mm}$ diameter and 200mm long were used. The moulds were assembled, placed on a rigid horizontal surface and filled with concrete and then compacted to remove the entrapped air, with no segregation. The concrete was then placed in layers of $50 \mathrm{~mm}$ and then vibrated. The surface was smoothened and left for $24 \mathrm{hrs}$ before dismantling the moulds and then cured by immersing in water. The specimens were removed from water, weighed, measured at 28 days of maturity to determine the area and the density of the concrete.

\section{Flexural strength (KS $595-8: 1986)$}

Flexural strength is one of the measures of tensile strength of concrete. It is a measure of the unreinforced concrete beam to resist failure in bending. Although concrete is not normally designed to resist direct tension, the knowledge of tensile strength is of value in estimating the load under which the concrete will crack. The absence of cracking is of considerable importance in maintaining the continuity of a concrete structure and in many cases the prevention of corrosion of reinforcement.

The flexural strength is expressed as Modulus of Rupture which was determined by the three point loading or the Center Point loading.

\section{RESULTS AND DISCUSSION}

\section{(i) Workability}

In the table 1, the results obtained from the slump test showed that workability of the concrete decreased marginally with the addition of the limestone. This was attributed to the porous nature of the Limestone aggregates which took in the water as pore water. 
Table 1: Workability for different percentage replacement of crushed limestone aggregates

\begin{tabular}{|l|c|}
\hline Mix Proportion & $\begin{array}{l}\text { Measured } \\
\text { Slump }\end{array}$ \\
\hline Control Mix & 80 \\
\hline 25\% Replacement (M25) & 75 \\
\hline $50 \%$ Replacement (M50) & 75 \\
\hline $75 \%$ Replacement (M75) & 70 \\
\hline $100 \%$ Replacement & 70 \\
(M100) & \\
\hline
\end{tabular}

\section{(ii) Compressive Strength}

In table 2 the compression strength values where obtained after crushing cubes at $3,7,14$, and 28 days of maturity as per the requirements of the Kenya Standards for compression testing KS 594 -7: 1986.

Table 2: Compressive strength test results

\begin{tabular}{|c|c|c|c|c|c|}
\hline \multirow{2}{*}{$\begin{array}{c}\text { Mix } \\
\text { No. }\end{array}$} & \multirow{2}{*}{$\begin{array}{c}\text { Replacement } \\
\text { Percentage }\end{array}$} & \multicolumn{5}{|c|}{$\begin{array}{c}\text { Compression Strength } \\
\left(\mathrm{Kn} / \mathrm{m}^{3}\right)\end{array}$} \\
\cline { 3 - 6 } & & 3days & 7 days & 14 day & 28 day \\
\hline M0 & $0 \%$ & 11 & 15 & 18 & 21 \\
\hline M25 & $25 \%$ & 12 & 15 & 16 & 19 \\
\hline M50 & $50 \%$ & 11 & 14 & 16 & 19 \\
\hline M75 & $75 \%$ & 16 & 18 & 19 & 21 \\
\hline M100 & $100 \%$ & 11 & 12 & 15 & 18 \\
\hline
\end{tabular}

Figure 1 (a) illustrates the curves obtained from the compression test of moulds cured in 3, 7, 14, and 28 days as per the requirements of the Kenya Standards for compression testing KS 594 -7: 1986. The compression strength was plotted against the percentage replacement of the limestone aggregates. The curve indicated a trend of high strength values at $75 \%$ replacement otherwise the resultant strength values where almost the same at 28days. Figure (b) presented that the strengths development trend to increase with maturity and within the requirements of the concrete class 20 . The maximum strengths observed where within the allowable limits per maturity four stages

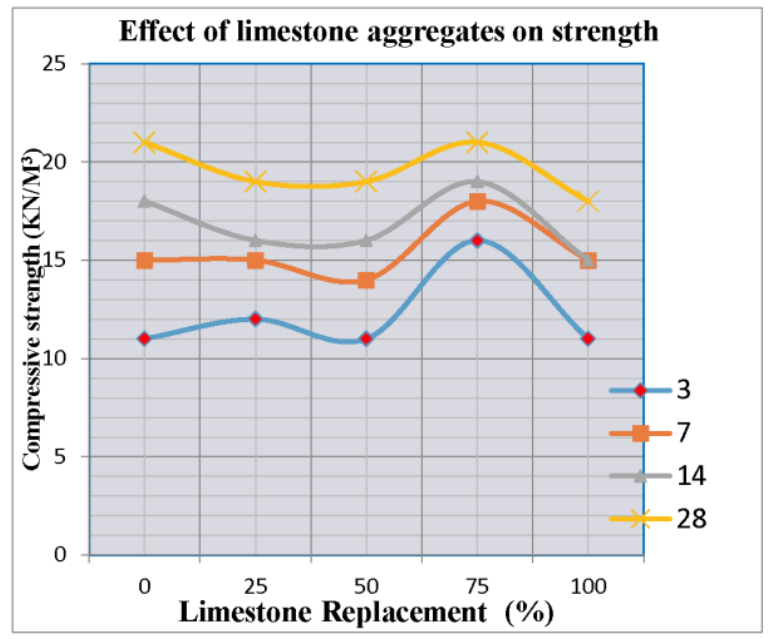

Figure 1 (a) Limestone effects on compression

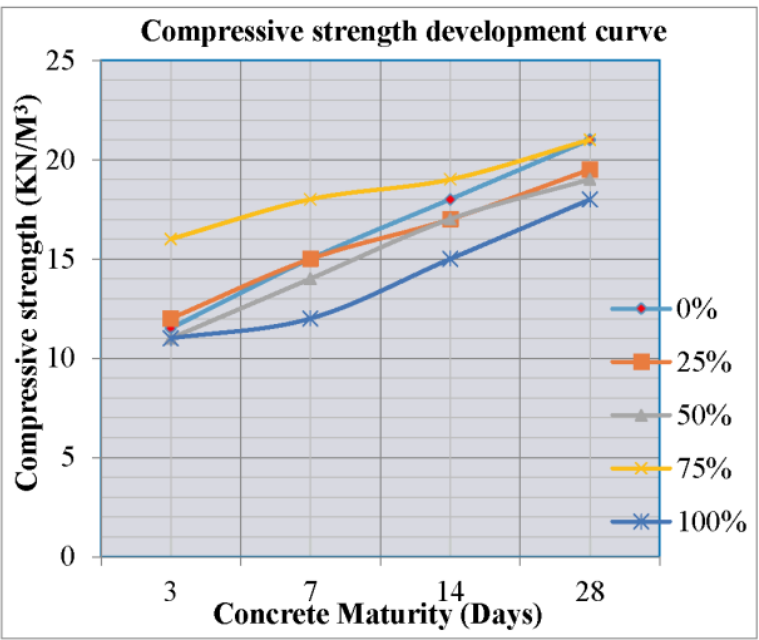

Figure 1 (b) Compression strength development curve

\section{CONCLUSIONS AND RECOMMENDATIONS}

Crushed limestone aggregate concrete had reduced density compared to that with the normal concrete aggregates; a reduction in concrete density of up to $8.1 \%$ was observed when limestone in the sample mix M100 replaced $100 \%$ by weight of the coarse aggregate. This gives a significant reduction of the weight of the products and when used in building will reduce the overall dead load of the concrete structures translating to smaller dimension.

The concrete strength characteristics observed in the control and the other mixes consisting of limestone replacement where within limits required by the standard. This research would recommend the use of crushed limestone to be used as a natural aggregate in concrete production but best results $75 \%$ replacement will yield maximum benefit of strength characteristics.

\section{REFERENCES}

[1] Barbosa, F. S, Farage, M. C. R, Beaucour, A.-L. and Ortola, S., 2012, Evaluation of aggregate gradation in lightweight concrete via image processing, Construction and Building Materials,29(4), 7-11.

[2] Cities alliance, 2012., Annual report on Cities without slums. http://www.citiesalliance.org, accessed 21st October, 2012.

[3] Cui, H. Z, Lo, T. Y, Memon, S. A, and Xu W., 2012, Effect of lightweight aggregates on the mechanical properties and brittleness of lightweight aggregate concrete, Construction and Building Materials, 35(10),2012149-158

[4] ESCSI, Back-up statistics to building bridges and marine structures with structural lightweight aggregate concrete, Expanded Shale, Clay, and Slate Institute, 2001.

[5] Hamid Shahrabadi et al. Effect of limestone on the mechanical properties of concrete containing silica fume and fly ash. JMES, 2017 Volume 8, Issue 2, Pp 457-466

[6] Hossain, K. M. A, 2006, Blended Cement and Lightweight Concrete using Scoria: Mix Design, Strength, Durability and Heat Insulation Characteristics. Physical Sciences,

[7] Bhaskar Desai et al, 2014. Some Studies on Mode-II Fracture of Artificial Light Weight Silica Fume Pelletized Aggregate Concrete. International Journal of Civil Engineering and Technology (IJCIET), ISSN 0976, Vol. 5, Issue 2, 2014, pp. 33-51 
[8] Kenya National Bureau of Statistics, 2010. "Kenya 2009 Population and Housing Census Highlights" <http//www.knbs.org.ke/population2009.pdf>

[9] Kockal, N. U, and Ozturan, T., 2011,. "Durability of lightweight concretes with lightweight fly ash aggregates, Construction and Building Materials, 25(3), 2011, pp 1430-1438.

[10] Kockal, N. U. and Ozturan, T., 2010, Effects of lightweight fly ash aggregate properties on the behavior of lightweight concretes, Journal of Hazardous Materials, 179(1-3),pp 954-965.

[11] Mouli, M. \& Khelafi, H, 2008,. Performance Characteristics of lightweight aggregates concrete containing natural pozzolan. Building and Environment, 43, 31-36. http://www.escsi.org/

[12] Polat, R, Demirboğa, R, Karakoç, M. B., and Türkmen, İ, 2010, The influence of lightweight aggregate on the physico-mechanical properties of concrete exposed to freeze-thaw cycles, Cold Regions Science and Technology, 60(1), 2010, pp 51-56.

[13] Seyed Alireza Zareei , Farshad Ameri , Farzan Dorostkar, Shahriar Shiran (2017) Partial Replacement of Limestone and Silica Powder as a Substitution of Cement in Lightweight Aggregate Concrete. Civil Engineering Journal ISSN: 2476-3055 pg 727-740

[14] Wang, H. Y, 2007, Study on durability of densified highperformance lightweight aggregate concrete, Computers and Concrete, 4(6), 2007, 499-510.

[15] Wang, H. Y, 2009, Durability of self-consolidating lightweight aggregate concrete using dredged silt, Construction and Building Materials, 23(6),2009, 2332-2337.

[16] Yehia, S., Alhamaydeh, M. and Farrag, S., 2014,. High strength lightweight SCC matrix with partial normal weight coarse aggregate replacement: strength and durability evaluations, ASCE Journal of Materials in Civil engineering, 